\title{
Vision of Effective Leadership
}

\author{
Robert Cote $^{1}$ \\ ${ }^{1}$ Lindenwood University, St. Charles, USA \\ Correspondence: Dr. Robert Cote, Assistant Professor, Lindenwood University, St. Charles, Missouri 63301, USA.
}

Received: August 1, 2017

Accepted: August 21, 2017

Online Published: September 13, 2017

doi:10.5430/ijba.v8n6p1

URL: https://doi.org/10.5430/ijba.v8n6p1

\begin{abstract}
The purpose of the paper will be to develop a framework for the objective evaluation of leadership styles, including effective and dark side leadership. In the framework, various leadership approaches are identified, such as (1) Transformational Leadership, (2) Transactional Leadership, (3) Charismatic Leadership, (4) Situational Leadership, (5) Pseudo-Transformational Leadership. Using this framework, two historical leaders will be compared and contrasted according to their leadership style. In the final section, dark side leadership dimensions will be reviewed and evaluated. Based on the framework, a vision of leadership strategy plan will be completed for incorporating effective leadership, including recognizing darker characteristics and providing solutions to avoid the emergence of dark leadership.
\end{abstract}

Keywords: leadership, dark side leadership, effective leadership, transformational, transactional, situational, trait approach, followers, leaders, $21^{\text {st }}$ century, leadership strategy

\section{Leadership Introduction}

Leadership has been researched over the last five decades, resulting in the development of 65 classifications and 350 definitions with an emphasis on understanding the positive "good" characteristics leading to the glamorization of leadership today. As a result, leaders are considered the saviors and heroes for organizations in crisis. Overall, research supports the argument that leadership is good in organizations (Bligh, Kohles, Pearce, Justin, \& Stovall, 2007).

Leadership is considered a relationship that is reciprocal process, whereby the leader influences the followers through persuasion to achieve common organizational goals (Hersey, Blanchard, \& Natemeyer, 1979; Hogan \& Kaiser, 2005). Based on leadership, the following components are central, which are: (1) leadership occurs in group situations, (2) leadership is a process that is a transactional event that occurs between leader and followers, (3) leadership involves influencing followers, and (4) leadership includes goal attainment (Northouse, 2016).

Bennis (1982) explains the results of a study conducted with 90 CEO's to learn which competencies were shared and incorporated in their roles to successfully translate intention into reality in organizations, while maintaining consistency. Based on his findings, the effective CEO's were able to create a clear vision, influence followers by communicating the vision to gain support, maintain organizational direction through persistence and consistency, and the capacity to empower followers to tap and harness the energy to achieve desired results or outcomes (Bennis, 1982).

Most recently, the darker side of leadership has become the focus of increased research on exploring the characteristics, causes, and outcomes attributed to the highly publicized corporate scandals and unethical behavior, i.e., WorldCom, Enron, Arthur Anderson, Tyco, and Madoff (Trevino \& Brown, 2005). Unlike good leadership, the darker side leadership can be considered destructive leadership defined by Einarsen, Aasland, and Skogstad (2007) as "a systematic and repeated behavior by a leader, supervisor or manager that violates the legitimate interest of the organization by undermining and/or sabotaging the organization's goals, tasks, resources, and effectiveness and/or the motivation, well-being or job satisfaction of subordinates" (p. 208).

Based on the development of leadership over the last century, this next section will evaluate and analyze a sampling of effective leadership approaches focusing on the leader-follower relationship, by which a leader influences and motivates followers to achieve goal accomplishment both positively and negatively. 


\section{Leadership Approaches}

The following leadership approaches will explore the positive and negative aspects of leader-follower dynamics, which are: (1) Transformational Leadership, (2) Charismatic Leadership, (3) Transactional Leadership, and (4) Situational Leadership.

\subsection{Transformational Leadership}

Transformational leadership is one of the newer types of leadership researched with a focus on the needs of today's employees, due to the times of uncertainty when employees need to be inspired and empowered. For transformational leadership, it is a process when the leader and follower engage and form a connection that raises the level of motivation and morality to a higher level (Parry, \& Proctor-Thomson, 2002).

Transformational leadership occurs when leaders, according to Bass (1990) "inspire, energize, and intellectually stimulate their employees" (p.19). He believes through adequate training, managers can learn the necessary techniques and qualities to make them proficient to become transformational leaders. This type of leader focuses on the follower's values, emotions, ethics, long-term goals while assessing motives, and satisfying their needs in a transformational process that changes people. On the positive side of leadership, transformational leadership can be viewed in a diverse range of leadership roles. In the organization, leaders can influence followers on a one-to-one connection, larger groups, or the entire organization. As organizations precipitate change, the leader plays a pivotal role while the transformational process is dependent on the strong bond between leader and follower (Northouse, 2016).

\subsection{Charismatic Leadership}

Charismatic leadership has been a phenomenon researched for the last 15 years and is often described in ways that may be synonymous with transformational leadership (Aalito-Marjosola \& Takala, 2000; Howell \& Avolio, 1992). For charismatic leaders, they act in a unique way with their followers based on personal characteristics and specific types of behavior, including: (1) strong role models for the adoption of beliefs and values in followers, (2) competent to followers, (3) articulate ideological goals with moral overtones, (4) communicate high expectations to followers, and (5) arouse task-oriented movement in followers (Northouse, 2016).

\subsection{Transactional Leadership}

Transactional leadership focuses on the exchanges between the leader and the employee. For transactional leaders, they are task-oriented and focus on clarifying employee's roles and task requirements by providing specified rewards and punishment based on performance outcomes (Burns, 2008). An example of a contingent reward would be a sales professional who has exceeded his/her quota will be awarded a free membership to the gym. This is more of a positive reinforcement and effective with employees. An example for punishment would be management-by-exception. A supervisor monitors a sales professional's interaction with a customer. The leader can follow an active or passive approach. For the active approach, the leader will provide immediate feedback with a corrective action if sales professional does not discuss the required sales pitch. For the passive approach, the leader will have provided feedback after the interaction with the customer (Northouse, 2016; Kuhnert, 1994, Kuhnert \& Lewis, 1987). Management-by-exception use more of a negative reinforcement versus positive reinforcement with contingent rewards. Based on transformational (relationship/behavior oriented) and transactional (task oriented), successful leaders display both styles of leadership (Zhu, Riggio, \& Avolio, 2011).

\subsection{Situational Leadership}

Situational leadership focuses on how a leader motivates and influences followers in situations. For this style of leadership to be successful, leaders need to adapt their style to the demands of the followers in different situations. Leadership is focused on two types of dimensions, which are directive and supportive. Leaders evaluate and assess employees based on competence and commitment to perform tasks. Depending on the situation and employee's motivation to complete a task, leaders will change the degree in which they are directive or supportive in meeting the changing needs of employees (Northouse, 2016).

In the last 30 years, situational leadership has experienced many changes and advancements. In 1985, the Situational Leadership II (SLII) model was developed to replace Situational Leadership I (SLI). Compared to the SLI model, the four styles of leadership and development of subordinates were added. In the SLII model, the leadership styles are labeled in the four quadrants to conceptualize the different styles of leadership, which are: (1) style 1: directing high directive/low-supportive (2) style 2: coaching - high-directive/high-supportive, (3) style 3: supporting high-supportive/low-directive, and (4) style 4: delegating - low-supportive/low-directive (Blanchard, Zigrami, \& 
Nelson, 1993; Hersey \& Blanchard, 1996).

For the addition of the development level of followers, according to Blanchard et al. (1993), "refers to the extent to which a person has mastered the skills necessary for the task at hand and has developed a positive attitude towards the task (p. 27). The development levels are based on level of competency, which are: (1) development level 1 - new to task with low competence/high commitment, (2) development level 2 - developed some competence may need more supportive behavior from leader, and (3) development level 3 - has moderate to high competence may need high supportive/low directive behavior, and (4) development level 4 - highest competence with high commitment/high competence. Based on the revised SLII model, this provides leaders the flexibility to adapt their leadership style based on the situation, difficulty of the task, and the development level of the follower. For situational leadership to have a positive effect, leaders need to understand and determine where followers are on the developmental continuum and adapt the style of leadership necessary to match the level of commitment and competence in achieving a task (Blanchard et al., 1993).

Based on the four type of leadership discussed, each has their own merit in leading followers in organizations. Transformation Leadership focuses on inspiring, motivating and empowering individuals to be their best. Transactional Leaders focus on the exchange with individuals by setting goals and monitoring progress, and providing rewards or punishment based on performance. While Pseudo-Transformational Leaders, may lead followers in a negative, unethical and moral directions. For Charismatic Leaders, they are similar to Transformational Leaders with a unique way of using personal characteristics and behaviors to get results. Lastly, Situational Leaders focus on how a leader motivates and influences followers in situations. In order for the leader to be successful, they need to adapt their style to the demands of the followers in different situations.

The next section will review a dark side leadership approach and identify/evaluate dark leadership characteristics, i.e., Taxonomy of dark side characteristics and Pseudo-Transformational Leadership. The remaining paper will cover vision of leadership and successful strategy for effective leadership.

\section{Dark Side Leadership Style}

The purpose of this section, is review pseudo-transformational leadership approach and evaluate the framework for leadership while identifying darker leader characteristics that may be present in leaders. In the final section, a plan of action will be developed with solutions to overcome darker elements with a timeline for completing these action steps.

\subsection{Pseudo-Transformational Leadership}

Pseudo-transformational leadership would be considered the negative side of leadership. Parry and Proctor-Thomson (2002) explain that transformational leadership may not always elevate followers to a higher ground, instead "depending on the leader's vision and personal motivation, may in fact lead followers in negative, unethical and moral directions" (p. 75). Instead of transforming people in a positive way, leaders use their power and influence in a negative way. For example, Saddam Husseim, Adolf Hitler, and Jim Jones were self-consumed, power-oriented, and exploitive with warped moral values. They used their leadership strengths for their own personal interests instead of the interest of their followers (Northouse, 2016). The next section will further evaluate dark side characteristics using a taxonomy table in 3 dimensions.

\subsection{Dark side Characteristics}

Many leaders have been impacted by dark side characteristics throughout their career. Although, some of a lesser degree than others. For leaders, dark side behaviors would occur in times of stress, being overwhelmed in meeting timelines, and tired from long hours. For the extent of evaluating one's strengths and weaknesses, Hogan and Kaiser (2015) developed the following dark side themes and taxonomy for a leader's personality (see table 1) divided into 11 dimensions, which are: (1) dimension 1 - excitable, cautious, skeptical, reserved, and leisurely, (2) dimension 2 bold, mischievous, colorful, and imaginative, and (3) dimension 3 - diligent and dutiful. In subsequent research, the inventory of dimensions is a good predictor of leadership derailment. Based on characteristics, high scores have positive short-term impact while having negative consequences long-term (Hogan \& Kaiser, 2006; Hogan \& Kaiser, 2015). 
Table 1. Taxonomy of the dark side of leadership personality

\begin{tabular}{|c|c|c|c|}
\hline \multicolumn{4}{|l|}{ Dimension } \\
\hline \multicolumn{4}{|c|}{ Factor 1 - Intimidation: gaining security by threatening people and scaring them away } \\
\hline Excitable & $\begin{array}{l}\text { Unstable and intense } \\
\text { relationships, inappropriate } \\
\text { anger }\end{array}$ & Energy and Enthusiasm & Others begin to avoid \\
\hline Cautious & $\begin{array}{l}\text { Hypersensitivity to rejection and } \\
\text { criticism }\end{array}$ & Make few mistakes & $\begin{array}{l}\text { Risk aversion and } \\
\text { Indecisiveness }\end{array}$ \\
\hline Skeptical & $\begin{array}{l}\text { Motives are interpreted as } \\
\text { malevolent: Mistrustful and } \\
\text { suspicious }\end{array}$ & $\begin{array}{l}\text { Insightful about politics } \\
\text { within organization }\end{array}$ & $\begin{array}{l}\text { Mistrustful, vindictive and } \\
\text { litigious }\end{array}$ \\
\hline Reserved & $\begin{array}{l}\text { Detached, cold, tough, and } \\
\text { uncommunicative }\end{array}$ & $\begin{array}{l}\text { Resolute under pressure and } \\
\text { tough }\end{array}$ & $\begin{array}{l}\text { Insensitive to moral issues } \\
\text { and uncommunicative }\end{array}$ \\
\hline Leisurely & $\begin{array}{l}\text { Procrastinating, stubborn, and } \\
\text { passively resistant to } \\
\text { performance improvement }\end{array}$ & $\begin{array}{l}\text { Appear cooperative and } \\
\text { charming }\end{array}$ & $\begin{array}{l}\text { Passive aggressive behavior } \\
\text { (mean) }\end{array}$ \\
\hline \multicolumn{4}{|c|}{ Factor 2 - Seductive and flirtatious: winning recognition with charm and self promotion } \\
\hline Bold & $\begin{array}{l}\text { Arrogant, grandiose, and } \\
\text { self-importance }\end{array}$ & $\begin{array}{l}\text { Confidence, courage, and } \\
\text { charisma }\end{array}$ & $\begin{array}{l}\text { Inability to learn from } \\
\text { mistakes and admit mistakes }\end{array}$ \\
\hline Mischievous & $\begin{array}{l}\text { Dissembling, manipulative, } \\
\text { impulsive, and limit testing }\end{array}$ & Risk taker and charming & $\begin{array}{l}\text { Ignore rules, exploitive, and } \\
\text { lies to others }\end{array}$ \\
\hline Colorful & $\begin{array}{l}\text { Self-dramatizer, theatrical, and } \\
\text { attention seeker }\end{array}$ & $\begin{array}{l}\text { Flirtatious, engaging, and } \\
\text { entertaining }\end{array}$ & $\begin{array}{l}\text { Overly dramatic, attention } \\
\text { seeker, and distracting }\end{array}$ \\
\hline Imaginative & $\begin{array}{l}\text { Interesting, eccentric flights of } \\
\text { ideas (grandiose) }\end{array}$ & $\begin{array}{l}\text { Out of box thinker and } \\
\text { visionary }\end{array}$ & $\begin{array}{l}\text { Bad judgment leads to loss of } \\
\text { credibility }\end{array}$ \\
\hline \multicolumn{4}{|c|}{ Factor 3 - Ingratiation: ensuring approval by loyalty and becoming indispensable } \\
\hline Diligent & Hard to please, perfectionist & $\begin{array}{l}\text { High standards, hard worker; } \\
\text { self-sacrificing }\end{array}$ & $\begin{array}{l}\text { Rigid, over controlling, and } \\
\text { micromanager }\end{array}$ \\
\hline Dutiful & $\begin{array}{l}\text { Difficulty making decisions and } \\
\text { unwillingness to disagree with } \\
\text { upper management }\end{array}$ & $\begin{array}{l}\text { Considerate, team player, } \\
\text { keep boss informed }\end{array}$ & $\begin{array}{l}\text { Overly concerned about } \\
\text { pleasing upper management, } \\
\text { indecisive }\end{array}$ \\
\hline
\end{tabular}

(Hogan \& Kaiser, 2006; Hogan \& Kaiser, 2015).

In reviewing factor 1, the characteristics in this dimension, would best describe a leader early in their career due to leadership immaturity, i.e., excitable, cautious, reserved, and leisurely. As an excitable leader, this could be due to intensity resulting in being volatile and unpredictable. On the positive side, being a leader possessing these characteristics provided the following short-term results, which are energetic, enthusiastic, makes few mistakes, insightful, tough under pressure, charming, and cooperative. On the negative side, long-term weaknesses are co-workers begin to avoid due to unfavorable behaviors, indecisiveness, risk-aversion, uncommunicative, and passive aggressive meanness (Hogan \& Kaiser, 2006; Hogan \& Kaiser, 2015).

In reviewing factor 2 , the characteristics bold, mischievous, colorful, and imaginative would be the best adjectives to describe a charismatic leader demonstrating self-promotion. For leaders, who become bolder with an increase in confidence, courage, and charisma provide a short term benefits with followers. Although leaders must admit mistakes and continually learn from others to minimize leadership mistakes. Out of the other three dimensions, charming, entertaining, engaging, visionary, and out of the box thinker would be positives in describing a number of leader's style. Unfortunately, the negative aspects of this dimension (i.e., ignore rules, lie, distracting, and bad 
judgment) are behaviors that will destroy relationships with employees and colleagues (Hogan \& Kaiser, 2006; Hogan \& Kaiser, 2015).

In reviewing factor 3, the characteristics diligent and dutiful full would best describe a common leadership style today. Partially, due to many micromanagers in the past that would be considered incompetent and inability to lead effectively. At times, leaders may be considered a perfectionist and difficult to please, while being a hard worker expecting high standards from their team. Being dutiful, has a team player focus, while considerate, and making independent decisions that may impact employees positively. As a leader, compromising on decisions to avoid conflict with upper management can build relationships. However, leaders possessing bold characteristic eventually will take over creating the confidence to disagree with management (Hogan \& Kaiser, 2006; Hogan \& Kaiser, 2015).

Can leaders overcome dark side leadership? The takeaway from the Kaiser and Hogan (2006 \& 2015) research on dark side characteristics. The inventory of dimensions is a good predictor of leadership derailment. Based on characteristics, high scores have positive short-term impact while having negative consequences long-term. If leaders exhibit too much dark side characteristics, they will most likely get fired. If leaders exhibit too little dark side characteristics, they will be overlooked. Other factors to consider, dark side leaders erode and destroys subordinate trust, lack team building, and affect organizational performance (Hogan \& Kaiser, 2006; Hogan \& Kaiser, 2015).

\section{Leadership Historical Analysis}

In the following sections, Herb Kelleher the positive leader and Bernie Ebbers the darker will be analyzed and compared according to their leadership style. In the analysis, the following information will be reviewed: (1) background overview on leader and company, (2) strengths and weaknesses, and (4) successes and failures in leadership, and (4) comparison of similarities and differences in leadership

\subsection{Herb Kelleher Overview}

In 1966, Herb Kelleher and his business colleague, Rollin King decided to start an airline called Southwest Airline (SWA). Although their idea seemed outlandish at the time, their business plan was created to fly passengers across short distances, cost effective, and on time as a no frills airline. At the time, the airline would be free of federal price regulations by flying within the Texas border, which meant a drastic reduction in costs for the airlines (PBS, 2009)

In 1971, SWA was incorporated and began flying in Texas with three Boeings' 737 with fewer than 70 employees to three main cities, which are Houston, Dallas, and San Antonio. In 1973, after two years of operation, SWA was a profitable organization and never looked back (PBS, 2009; Southwest Airlines, 2017).

Today, SWA operates in more than 101 cities in United States with more than 3,900 flights daily from coast to coast, which makes SWA the largest United States (US) carrier with domestic airline departures. SWA's currently operates more than 500 Boeing 737 jets with an age of approximately 9 years old. Compared to the 70 employees in 1971, SWA has more than 50,000 employees throughout the organization (Southwest Airlines, 2017).

\subsection{Herb Kelleher Positive Leader}

How has Herb Kelleher been a successful leader for SWA? His leadership style is considered charismatic and transformational. As a charismatic leader, Herb Kelleher has a strong desire to influence employees with a dominant, self-confident personality while having a strong sense of moral values. As a transformational leader, Herb Kelleher has the ability to change and transform his employees through a process of influence that reciprocates a relationship that benefits both parties (Northouse, 2010).

Herb Kelleher believes six key personal attributes are necessary for successful leadership, which is good health, reasonable intelligence, a lengthy attention span, an optimistic disposition, perseverance, and a love for people. He also attributes acquirable skills that are the most contributors to success, which are (1) broad knowledge and education, (2) good listening skills, (3) sound judgment, (4) ability to be a passionate advocate, (5) ability to separate important from unimportant things, (6) ability to be goal oriented with focus on priorities, and (7) pleasant skepticism (Fawcett, Brau, Rhoads, Whitlark, \& Fawcett, 2008).

Herb Kelleher has been a legend at SWA because of his unique set of competencies, which are: (1) established a culture environment in which diversity, dignity and respect are valued, (2) developed a value-added leadership development program based on the philosophy "hire for attitude and train for skill", (3) stayed in touch with employees through effective communication and sense of humor, (4) inspired through commitment, putting employees first, (5) created a shared vision by influencing employees and translating that vision into action, and (6) developed innovative strategies keeping SWA a successful airline in a competitive marketplace (Krames, 2003).

Herb Kelleher, CEO of Southwest Airlines (SWA) has spent his majority of his tenure cultivating a working 
environment that inspires creativity and passion in the employees. Herb Kelleher has taken an alternative path in putting his employees first, while emphasizing his workforce as the most vital source providing a competitive advantage. As a result, SWA has set an unparalleled accomplishment in the standard in the airline industry by consistently being profitable for Forty-four years and considered one of the best places to work (Fawcett et al., 2008; Southwest Airlines; 2017).

All good leaders eventually need to step down from their role. In 2008, Herb Kelleher passed the baton to Gary Kelley to become the Chairman of the Board and in 2004 became the CEO. In 2017, SWA airline continues to rank eighth as one of the world's most admired companies and Gary ranked fifth as top underrated CEO (Southwest Airlines, 2017).

\subsection{Bernie Ebbers Overview}

In 1982, the deregulation of the AT\&T telecommunications giant offered and opportunity for Bernie Ebbers to quickly move from motel chain owner to fiber optic network magnet. Ebbers and his business associates started Long-Distance Discount Services (LDDS), which is a re-seller company that purchased long-distance services from AT\&T at a discounted rate and resold to customers at a higher retail price. Initially, LDDS was not profitable for the first two years and Bernie Ebbers used his equity from his motel purchases and gained control of LDDS in 1985 where he was named Chief Executive Officer (Trevino \& Brown, 2005).

Over the next ten years, LDDS acquired over 60 independent telecommunication companies and suppliers, including Advantage, Wiltel, and MFS Communications. In 1995, LDDS changed its name to World Com and Bernie Ebbers quest for expansion, he started to build a fiber optic network across Europe to compete market leaders Sprint. In 1998 , World Com purchased MCI for $\$ 37$ billion, which was three times the size of World Com while providing additional resources and industry clout (Trevino \& Brown, 2005).

In 1999, Bernie Ebbers reached the pinnacle of his success. World Com stock was at an all time high of $\$ 75$ a share. He continued to focus on efficiency by reducing operating costs, including selling corporate jets, reducing MCI staff, and expense accounts for staff. According to Trevino and Brown (2005), Bernie Ebbers was "viewed by colleagues and members of the local community in Mississippi as a responsible business leader who was willing to give back to the community" (p. 91). He taught Sunday school at the local Baptist church, invested his wealth in company stocks, and volunteered at a Jackson restaurant for the needy.

How does a CEO of a billion-dollar company change from a rock star leader to a leader of the dark side? In the next section, Bernie Ebbers leadership will be further evaluated and analyzed.

\subsection{Bernie Ebbers Dark Side Leader}

Bernie Ebbers was the founder and CEO of LDDS, which later became World Com. As he became the leading figure with his visionary approach in the telecommunications industry, his image was not perceived the norm and considered an outsider maverick known for his cowboy boots and low-key dress attire. His simple charm and charismatic leadership style inspired and influenced employees to exceed extraordinary levels of performance and personal loyalty. He rewarded his employees with perks and bonuses to show his loyalty while establishing a culture where decisions throughout the organization were unchallenged (Padgett, 2002; Trevino \& Brown, 2005).

However, there was another side of Bernie Ebbers leadership that was considered his darker side. He utilized his charismatic leadership and communication skills to conceal loans to him worth millions. Bernie Ebbers used his power to influence his followers by demanding "double digit" growth to increase company revenues, regardless of the means to achieve these goals. His focus on the "mergers and acquisition policy" was mainly to have World Com as a Wall Street favorite stock without evaluating and assessing strategies to reach this goal (Pandey \& Verma, 2005; Trevino \& Brown, 2005).

Bernie Ebbers perception as a transformational leader were misguided by his focus on reducing operating costs, increase market share, and revenue compared to empowering his employees. In leadership, the difference between an effective and ineffective leader is dependent on their traits, behaviors, and approach. For Bernie Ebbers, he made poor strategic decisions by being blinded by his own power and vision due to his own charismatic dark side leadership.

\section{Comparison of Similarities and Differences of Historical Leaders}

In comparing Herb Kelleher and Bernie Ebbers, they were similar in having charismatic transformational leadership styles in their organizations. Herb Kelleher believes his success was based on his attributes, skills, and competencies in cultivating a working environment that inspired creativity and passion in the employees. As a leader, he always 
put his employees first, while emphasizing his workforce as the most vital source and considered one of the best places to work.

Bernie Ebbers attributes his success by using his communication and interpersonal skills to influence and inspire employees to exceed expectations in achieving organizational goals while reciprocating his loyalty with bonuses and perks. Trevino and Brown (2005) share a comment from Doris Day, who has worked with him for more than 20 years "He is absolutely one of the most incredible human beings I have come in contact with...the lord is his CEO, as (He) is all of ours" (p. 91).

In comparing the differences between these two leaders, Herb Kelleher was always praised by his employees and the industry. In the 35 years as leader, he established a cultural environment based on respect, diversity, and dignity, developed a value-added leadership program, two-way communication process with employees, inspired employees by putting them first, and created a vision that was shared with the entire organization (Krames, 2003; Southwest Airlines, 2017).

Bernie Ebbers was perceived to be the transformational leader by his employees, colleagues, and community. However, in his quest to be recognized as the magnate of the telecommunications industry, he attracted a following that was inspired by his charismatic personality no-nonsense management style. In the end, Bernie Ebbers made bad decisions due to his dark side leadership which was blinded by his power and vision resulting in the World Com bubble bust.

\section{Vision of Effective Leadership}

The 11 dimensions of dark side leadership were evaluated and analyzed providing the short-term and long-term positive and negative aspects of dark leadership characteristics. In the continued research of effective leadership, characteristics of dark side leadership describe the potential behavior and are a predictor when a leader may self-destruct (Burke, 2006; Hogan \& Kaiser, 2006; Hogan \& Kaiser, 2015).

Leaders can also be vulnerable to dark leadership due to many factors, including a deeply ingrained leadership style, situations, behavior, stress, organizational environment, colleagues, and personality traits. In identifying, acknowledging, and managing these factors, leaders should reflect on past experiences and accept a deep change that may shift their behavior and prevent dark side leadership.

\section{An Effective Leadership Strategy}

Organizations are susceptible to negative and unethical outcomes under the direction of dark leaders. For overcoming dark side leadership, an effective leadership strategy was developed using leadership best practices to avoid the negative aspects of dark side leadership. As a benefit to the organization, the leadership strategy will have a focus on treating employees as human beings with a positive end result to motivate, inspire, empower. Based on effective leadership, employees treated with genuine care, will appreciate, and have concern for themselves and others, thus producing a unity emphasizing membership, synergy, and engagement.

The following best practices have been developed according to the definition of effective leadership by Northouse (2016), as "a process whereby an individual influences a group of individuals to achieve a common goal" (p. 6). Based on the effective approaches discussed in this paper, including transformational approach, transactional approach, trait approach, situational approach, and new trends in leadership. The goal of the leadership strategy is to share the best practices that will provide leaders with the tools and resources to influence employees and build a strong synergistic organizational culture.

\subsection{Transformational and Transactional Leaders}

Transformational leaders motivate and empower employees to do great things in times of change and uncertainty. These leaders are great role models for followers. They follow a core set of values and ethical principles that establishes trust and develops relationships. Transformational leaders inspire confidence and motivation in communicating the vision and expectations for goal attainment in an optimistic behavior. These leaders value creativity and autonomy from followers. They help followers overcome personal challenges and questions status quo. Transformational leaders provide support by understanding each followers needs and desires. They motivate and empower each follower through one-on-one coaching and mentoring to grow and become fully actualized.

Transactional leaders are effective by helping employees set goals, monitor goal progress, and reward or punish according to performance. Leaders may use contingent rewards driving positive reinforcement (promotion) or management-by-exception that involves negative reinforcement, negative feedback, or corrective actions for not meeting expectations. Transactional leaders do not focus on the employees needs or personal development. Instead, 
they focus on advancing their own agenda and employees task accomplishment. For effective leaders, they will use both transformational leadership to develop the relationships and transactional leadership to help employees accomplish tasks/goals (Bass, 2011; Kuhnert, 1994; Kuhnert \& Lewis, 1987).

\subsection{Trait Approach}

The trait approach has been effective with over 100 years of research data that emphasizes the important role of traits in the leadership process (Northouse, 2016). According to Goldberg, 1990; McCrae \& Costa (1987), "Big Five Key Traits" of leaders, include extroversion (outgoing), conscientiousness (dependable), openness to experience (innovative and creative), emotional intelligence (self-esteem, self-confident, and predictable), and agreeableness (warm, friendly, and approachable). Other traits to consider are honesty and integrity. Effective leaders can also be an ethical leader that is honest with followers and grounded with strong ethical principles that are followed on a daily basis. Leaders with honesty and integrity traits are successful in developing trust and respect with followers. This is similar to the transformational leadership approach.

\subsection{Situational Approach}

Situational leaders are effective with followers by focusing on leadership in situations. The leader motivates and influences the follower by adapting their leadership style based on the different situations. For each situation, the leader will focus on a directive or supportive behavior that is appropriate for each situation. Depending on the situation and follower, leaders will change their leadership style to high-low directive behavior or high-low supportive behavior to meet the needs of the employees. Directive approach will focus on helping the follower accomplish goals and tasks through directions, defining roles, evaluations, and how the goals will be achieved in a one-way communication process. Supportive approach focusses on helping followers feeling comfortable with themselves, provide support for social and emotional needs, and use a two-way communication process for achieving goals. For leaders, they evaluate and assess employees based on levels of development in competence and commitment necessary to perform tasks or accomplish goals. For this approach to be effective, leaders will assess the situation and the followers level of motivation to complete a task. This approach is effective by utilizing both behavior oriented (i.e., transformational leader) and task oriented (transactional leader). (Northouse, 2016)

\subsection{Effective Leaders of the $21^{\text {st }}$ Century}

What makes great leaders? How do leaders prepare to be effective leaders of the $21^{\text {st }}$ century? Torres (2013) conducted a survey with over 4000 companies, to determine the effectiveness of the leadership development programs. Based on the results, only 58\% of the companies lacked significant gaps in leadership talent and development programs crucial for effective leaders.

As a leader of the $21^{\text {st }}$ century, will require maintaining a competitive advantage in a globalized economy, managing information technology with increase in e-commerce, managing trends in workplace diversity, promote ethics based on core values and beliefs, and develop relationships with internal and external stakeholders. Instead of following the traditional assessments like narrow 360 surveys or outdated performance criteria, leadership in the 21 st century is defined and evidenced by three questions:

1. Where are you looking to anticipate the next change to your business model or your life?

2. What is the diversity measure of your personal and professional stakeholder network?

3. Are you courageous enough to abandon a practice that has made you successful in the past?

Based on the three questions, Torres (2013) explains leaders need to look into the future and anticipate opportunities and be prepared and ready to act. Leaders also need to break out of the comfort zone and develop relationships with different people, including physical, biological, political, socioeconomic, functional, and cultural differences. Having a diverse network of internal and external stakeholders, provides leaders with different perspectives, new information, and approaches for solving problems. Effective leaders of the $21^{\text {st }}$ century strive to be different and willing to take risks. Leadership is about coping with change. As the business world becomes more globalized, leaders doing things the same way is no longer an effective formula for success (Torres, 2013). Are you willing to take the courageous step into the $21^{\text {st }}$ century?

\section{Conclusion}

Leadership has evolved over the last 100 years from an autocratic centralized authority towards a democratic leader that delegates authority, follower participation, feedback from followers for completing tasks, and respect from both parties. Effective leaders today utilize a behavior oriented approach to better understand the needs of followers and be able to provide direction and support. Effective leaders also follow a task oriented approach to clarify objectives 
and job responsibilities, set expectations, coordinate activities, check progress, and evaluate performance (Daft, 2015).

Based on the multiple approaches evaluated and analyzed in this paper, including recent effective and dark side approaches used in organizations. First approach, transformational leaders is based on a behavior oriented focus with an emphasis on the connection and dependent on the strong bond between the leader and follower. Second approach, transactional leaders is based on a task-oriented focus with followers for clarifying roles and task/goals accomplishment by providing rewards or punishment. Third approach, situational leaders motivate and influence followers based on adapting the leader's behavior/style to meet the demands of the followers. Lastly, pseudo-transformational leaders use their personal agenda and vision to motivate followers in a negative way based on unethical behaviors. Based on this approach, research supports the negative consequences destructive leaders have on organizations, including degrading their credibility, erode and destroys subordinate trust, lack team building, and affect organizational performance.

In summary, effective leadership strategy was developed based on current leadership best practices and approaches to minimize or eliminate dark side leadership in organizations. Based on this strategy, leaders will treat followers as human beings with a focus on motivating, inspiring, and empowering followers. The goal of the "Vison of Effective Leadership" strategy is to provide leaders with tools and resources to influence employees and build a strong synergistic organizational culture. The difference between effective and destructive leadership is the consequences that may result in social good or social disaster (Bisoux, 2006; Hogan \& Kaiser, 2015).

\section{References}

Aaltio-Marjosola, I., \& Tuomo Takala, T. (2000). Charismatic leadership, manipulation and the complexity of organizational life. Journal of Workplace Learning, 12(4), 146-158. https://doi.org/10.1108/13665620010332750

Bass, B. (1990). From Transactional to Transformational Leadership: Learning to Share the Vision. Organizational Dynamics, 18(3), 19-31. https://doi.org/10.1016/0090-2616(90)90061-S

Bass, B. M., Bass, R., \& Bass, B. M. (2008). The Bass handbook of leadership: Theory, research, and managerial applications. New York: Free Press.

Bennis, W. (1982). The artform of leadership. Training and Development Journal, 44-46. Retrieved from Business Source Complete database.

Bisoux, T. (2005). What Makes Leaders GREAT. BizEd, 4(6), 40-45. Retrieved from Academic Search Premier Database.

Blanchard, K.H., Zigarmi, D., \& Nelson, R.B. (1993). Situational leadership after 25 years: a retrospective. The Journal of Leadership Studies, 1(1), 22. https://doi.org/10.1177/107179199300100104

Bligh, M., Kohles, J., Pearce, C., Justin, J., \& Stovall, J. (2007). When the Romance is Over: Follower Perspectives of Aversive Leadership. Applied Psychology: An International Review, 56(4), 528-557. https://doi.org/10.1111/j.1464-0597.2007.00303.x

Burke, R. (2006). Why leaders fail: exploring the darkside. International Journal of Manpower: Leadership in organizations, 27(1), 91-100. Retrieved from ABI/INFORM Global.

Daft, R. L., \& Lane, P. G. (2015). The leadership experience. Australia: Cengage Learning.

Einarsen, S., Aasland, M., \& Skogstad, A. (2007). Destructive leadership behaviour: A definition and conceptual model. The Leadership Quarterly, 18(3), 207-216. https://doi.org/10.1016/j.leaqua.2007.03.002

Fawcett, S., Brau, J., Rhoads, G., Whitlark, D., \& Fawcett, A. (2008). Spirituality and Organizational Culture: Cultivating the $\mathrm{ABCs}$ of an Inspiring Workplace. International Journal of Public Administration, 31(4), 420-438. https://doi.org/10.1080/01900690701590819

Hersey, P., \& Blanchard, K. (1996). Great ideas revisited: Life-cycle theory of leadership. Training \& Development, 50(1), 42. Retrieved from ABI/INFORM Global database

Hersey, P., Blanchard, K.H., \& Natemeyer, W.E., (1979). Situational Leadership, Perception, and the Impact of Power. Group \& Organization Studies (pre-1986), 4(4), 418. Retrieved from ABI/INFORM Global database

Hewes, R. (2017). Top ten traits of effective leaders. American Academy of Management. http://www.amanet.org/training/articles/top-ten-traits-of-great-leaders.aspx 
Higgs, M. (2009). The Good, the Bad and the Ugly: Leadership and Narcissism. Journal of Change Management, 9(2), 165-178. https://doi.org/10.1080/14697010902879111

Hogan, R., \& Kaiser, R. (2006). Research report: The dark side of discretion. Retrieved from http://www.hoganassessments.com/sites/default/files/Dark\%20Side\%20of\%20Discretion_0.pdf

Hogan, R., \& Kaiser, R. (2005). What We Know About Leadership. Review of General Psychology, 9(2), 169-180. https://doi.org/10.1037/1089-2680.9.2.169

Hogan, R., \& Kaiser, R. (2015). Research report: Reflections on the dark side. Retrieved from http://www.hoganassessments.com/thought-leadership/reflections-dark-side

Howell, J., \& Avolio, B. (1992). The ethics of charismatic leadership: submission or liberation? Executive (19389779), 6(2), 43-54. Retrieved from Business Source Complete database.

Krames, J. (2003). Performance culture. Executive Excellence, 20(11), 16-17. Retrieved from Business Source Complete database.

Northouse, P. G. (2016). Leadership: Theory and Practice ( $7^{\text {th }}$ ed.). Los Angeles, CA: Sage Publications, Inc.

Padgett, T., \& Baughn, A. (2002). The rise and fall of Bernie Ebbers. Time, 159(19), 56. Retrieved from Business Source Complete database.

Pandey, S., \& Verma, P. (2005). Organizational decline and turnaround: insights form the Worldcom case. Vision (09722629), 9(2), 51-65. Retrieved from Business Source Complete database.

Parry, K.W., \& Proctor-Thomson, S.B., (2002). Perceived integrity of transformational leaders in organisational settings. Journal of Business Ethics, 35(2), 75-96. Retrieved from ABI/INFORM Global.

PBS. (2009). Chasing the sun. Herb Kelleher. Retrieved from http://www.pbs.org/kcet/chasingthesun/innovators/hkelleher.html

Southwest Airlines. (2017). Southwest Media: Herb D. Kelleher. Retrieved from https://www.swamedia.com/pages/corporate-fact-sheet

Southwest Airlines. (2017). Southwest Media: corporate fact sheet. Retrieved from https://www.swamedia.com/pages/corporate-fact-sheet

Torres, R. (2013). What it Takes to be a Great Leader. Ted Conference. Lecture conducted from San Francisco, United States of America.

Treviño, L. K., M. E. Brown. (2005). The Role of Leaders in Influencing Unethical Behavior in the Workplace. Chapter 3 in Managing Organizational Deviance, 69-87.

Weichun, Z. R., Riggio, R. E., Avolio, B. J., \& Sosik, J. J. (2011, March 17). The Effect of Leadership on Follower Moral Identity: Does Transformational/Transactional Style Make a Difference?. Journal of Leadership \& Organizational Studies, 18(2), 150-163. https://doi.org/10.1177/1548051810396714 